Article

\title{
Clustering Smart City Services: Perceptions, Expectations, Responses
}

\author{
Miltiadis D. Lytras ${ }^{1,2}, *(\mathbb{D})$, Anna Visvizi ${ }^{1,3}$ (D) and Akila Sarirete ${ }^{2}$ \\ 1 School of Business \& Economics, Deree College-The American College of Greece, 153-42 Athens, Greece; \\ avisvizi@acg.edu \\ 2 Effat College of Engineering, Effat University, Jeddah P.O. Box 34689, Saudi Arabia; \\ asarirete@effatuniversity.edu.sa \\ 3 Effat College of Business, Effat University, Jeddah P.O. Box 34689, Saudi Arabia \\ * Correspondence: mlytras@acg.edu; Tel.: +30-210-600-9800
}

Received: 8 January 2019; Accepted: 15 March 2019; Published: 19 March 2019

check for updates

\begin{abstract}
Smart cities research evolved into one of the most vibrant fields of research and policy-making with sustainability and well-being becoming the bons mots of the debate. The business sector, i.e., the developers and the vendors, form an equally important group of stakeholders in this context. The question is to what extent that debate yields the kind of output that the end-users would expect and would consider useful and usable. A plethora of smart city services exists. Literature suggests that a myriad of new ICT-enhanced tools could find application in urban space. Methodologically speaking, the question is how to link these two meaningfully. The objective of this paper is to address this issue. To this end, smart city services are mapped and clusters of services are identified; end users' perceptions and expectations are identified and observations are drawn. The value added of this paper is threefold: (i) at the conceptual level, it adds new insights in the 'normative bias of smart cities research' thesis, (ii) at the empirical level, it typifies smart city services and clusters them, and (iii) it introduces a practical toolkit that policymakers, regulators, and the business sector might employ to query end-users' perceptions and expectations to effectively respond to citizens' needs.
\end{abstract}

Keywords: smart cities; information and communication technologies; technology clusters; innovation transfer; sustainability; analytics; ICTs; policy making

\section{Introduction}

Several dimensions of - what has been termed elsewhere-as 'the normative bias' of smart cities research thesis exist, including conceptual and empirical dimensions [1,2]. The term itself can be defined as the propensity of the research community to propose and discuss ever more sophisticated ICT-enhanced solutions to increasingly varied niche societal problems and needs. Whilst, in the long-run, this approach can defend itself, in the short-run it is necessary that valid functional connections between research on smart cities and the challenges faced by our society are identified, conceptualized, and exploited on an empirical ground. This requires that the great variety of stakeholders involved in the making of smart cities, including their needs, perceptions, expectations, and capacities, are factored into the smart cities debate equation. Whereas in the long-run, this approach can defend itself, in short-run, it is necessary that valid functional connections between research on smart cities and the challenges society faces are exploited. This requires that all stakeholders, their needs, perceptions, expectations, and capacities are factored in the discussion on ICT-enhanced services and their availability not only in cities and urban space but also in rural areas, including smart villages. The objective of this paper is to explore this issue. To this end, this paper 
examines the link between the end-users of smart services and the industry, i.e., the actual providers of ICT-enhanced applications meant to improve the wellbeing of citizens. The argument is structured as follows: first, based on literature review and outcomes of a pilot survey, criteria of categorization of smart services are established and the existing smart city services are divided into categories (clusters). As a result, a map of smart city services is devised. This map is then used to correlate citizens' perceptions and expectations of ICT-enhanced services with the awareness of vendors, policymakers, businesses in terms of what is needed and their capacity to respond to respective needs. In this way, in the concluding part, the key findings and a few recommendations are outlined.

\section{Querying the 'Normative Bias' of Smart Cities Research Thesis and Its Implications}

Fertilized by insights from a variety of disciplines, research on smart cities flourishes. Today, valuable insights to the debate are brought by researchers affiliating themselves with urban and regional studies, sociology, politics, international relations, political economy, and certainly computer science [3-6]. Ideally, the plethora of insights would have allowed the research community to build a multidimensional framework enabling a comprehensive study of issues and matters pertinent to the field of smart cities. But it is not the case; the field remains fragmented. To some extent, smart cities research has turned into a battlefield where diverse critical insights, diverging conceptual approaches, diverse normative imperatives, compete for the right to define the field. In addition, the computer science community sees smart cities research as a formidable testing ground for ideas based on the prospect of utilization of ever more sophisticated technologies. Clearly, this variety of approaches and perspectives applied to smart cities' research bears a great number of opportunities. At the moment, however, challenges seem to outweigh them. It is imperative therefore that an inter- and multi-disciplinary smart cities research agenda consolidates. To this end, more reflection on the conceptual precepts of the debate is needed. This includes the perennial questions of ontology and epistemology in smart cities research. Only in this way the vast field of smart cities research can be delineated, the numerous avenues of research that the field avails itself to can be identified, and finally, synergies exploited.

Consensus has consolidated that smart cities research ought to be part and parcel of the broader debate on sustainability. It is in this context that this paper highlights the interconnections and metaphors that emerge between the information and communication technology community (including computer science, information systems, computer networks, computer security etc.), social sciences, business-related research, and policy-makers. Establishing a strategic fit among these groups and, thereby, exploiting synergies that insights each of these groups bring to the discussion on smart cities constitutes a value contribution to this research. In this study, we are building upon our previously published research [1-3] and we are elaborating on the concept of smart city services and linking end-users' perceptions and expectations with the industry's awareness of and capacity to respond to these needs. In our research, a smart city service is defined as an integrated value carrier for the integration of citizens' and communities' quality of life and wellbeing based on advanced technological enablers (ICT).

The strategic objective of this research is three-fold:

- To understand what are the key technological enablers that support smart services in urban and rural areas. For this purpose, an extensive analysis of related research concluded to seven clusters of information and communication technologies that are discussed further in Section 3.

- To analyze what are the basic and innovative smart services under each category, showing the perceptions of smart city users about their intention in the use of these services and the added value they are bringing to them. In our previously published research [2] we concluded that three different major types of smart users exist. The motivation here is directly related to our so-called "normative bias" in smart cities research. One aspect of this bias can be the following: computer scientists have the capacity to deploy various technologies to offer smart cities services and to believe that these services will be accepted by users and will deliver value to them. The key 
question is if their expectations related to the adoption of their services meet also the perceptions and expectation of users of smart city services.

- To provide a policy-making, strategic roadmap for the readiness of smart city users and citizens to adopt specific types of services and to highlight which are the areas or services that will have limited interest. Obviously, such a contribution is significant for the Industry and the technology providers of smart city services. It is also critical for policymakers to reveal problematic areas or highlights areas and factors of concerns by smart city users.

The industry perception and awareness of usefulness and value-added of smart city services is also an ultimate target of this research: what to make of it? Can vendors, regulators, policy-makers, decision-makers, and businesses drive end-users' perception and awareness of smart city services? These additional questions will be answered as future research directions in the current study.

\section{Literature Review}

The pace of evolution in the domain of technology is amazing. In the group of well-established and streamline technologies like databases and computer networks, new arrivals of emerging technologies like the internet of things, cloud computing, big data, or virtual and augmented reality, bring new promises and new expectations to computer scientists. In the same context, citizens and communities are eager to enjoy secure, reliable, trusted, high performing services that will solve problems and will deliver value.

The overall understanding of the current evolution in ICT is that sophisticated information systems integrate the following features that can be integrated into smart cities solutions [1-3]:

- Databases and Data Warehouses technologies: advanced services for distributed, large scale data repositories capable of managing both structured and unstructured data [7]. In the context of smart city services, Data warehouse technology is a core technology. Issues related to data protection, data privacy, and data regulation have emerged and required delicate treatment.

- Content Management and Collaboration Platforms: The variety of data in structured and unstructured formats, as well as the variety of micro contents produced and consumed in different application contexts, such as social networks, e-commerce platforms and information or business portals, is challenging the design and provision of smart city services $[2,3,7]$.

- Advanced Computer Networks technology: a wide range of new generation computer networks has arrived providing a variety of constitutional and integrative components for smart city services. $5 \mathrm{~g}$ networks, Internet of Things together with mobile networking and distributed sensor networks are only a few of the possibilities of our times [7-11]. In the same context also social networks, social media and innovative collaborative, community-driven technologies $[9,10]$.

- Big Data and Analytics technology: Decision making oriented and policy-making driven approaches enhance the discovery of hidden patterns over big data and offer unique visualization options to policy and makers. Especially within the context of smart city research, these approaches have gained critical share and the potential for social impact is great [7,11-14].

- Social Mining and Social Impact technology: The utilization of users' profiles in local, and global context permit unforeseen capabilities for opinions mining, social mining and sentiment analysis over content and micro contents [7,15-17]. The utilization of these advanced computational techniques targets directly to the social component of smart city applications. With the increasing interest of businesses and the industry for personalized services and the recent updates on data privacy protection regulation measures set new limitations and barriers to a widespread taxonomy of social mining application for smart city services [18-20].

The evolution of information and communication technologies in the last decade resulted with the arrival of several highly promising technologies including Artificial Intelligence, Internet of Things, Cloud Computing, Cognitive Computing, Virtual, Mixed and Augmented Reality, Sensors and 5G 
networks, and many others. As a result, the design of urban applications and smart city systems becomes more complicated and sophisticated. At the same moment, there is a paradox that we must analyze further: while computer scientists and ICT experts claim for the value of these technologies to real users of smart cities applications, there are not many types of research that elaborate on the perceived value of sophisticated smart city services by real users.

In our view, technology has a critical social purpose in the context of smart cities. It must be beneficial for the society and has to respond to key social problems. Technology must be transparent and should deal with critical ethical concerns about security and privacy. Additionally, information and communication technologies in the context of smart cities research should take care of justice and equal treatment of all human entities, and by any means should not promote exclusion and must promote inclusiveness and social responsibility. One more feature of smart cities technology is that it must be flexible, open and extendable and should be deployed with the justification of resources and costs consumed. The adoption of ICT should be creative, promote collaboration and integration of ideas, beliefs, and opinions. Finally, yet importantly, ICT for smart cities research should build bridges between social, cultural and other gaps of citizens and capitalize on diversity.

Given the previous communication of features for smart cities technologies in the next section, we set up the context and the basis of our research model and investigation. From a huge, diverse and complementary literature review and industry review of ICTs and platforms, we conclude by six combined clusters of technology enablers and fifty pilot applications of smart city innovations. The ultimate objective of our study is to analyze how real users of smart city applications perceive the value of core technologies and relevant services towards the quality of their lives.

- Content Management systems

- Networking Technologies

- Data Warehouses \& Distributed Systems

- Analytics and Business Intelligence

- $\quad$ Emerging Technologies

- Smart City Innovation Technologies

In Figure 1, these clusters are highlighted. For our research, it is extremely important to link these clusters with value adding smart city services.

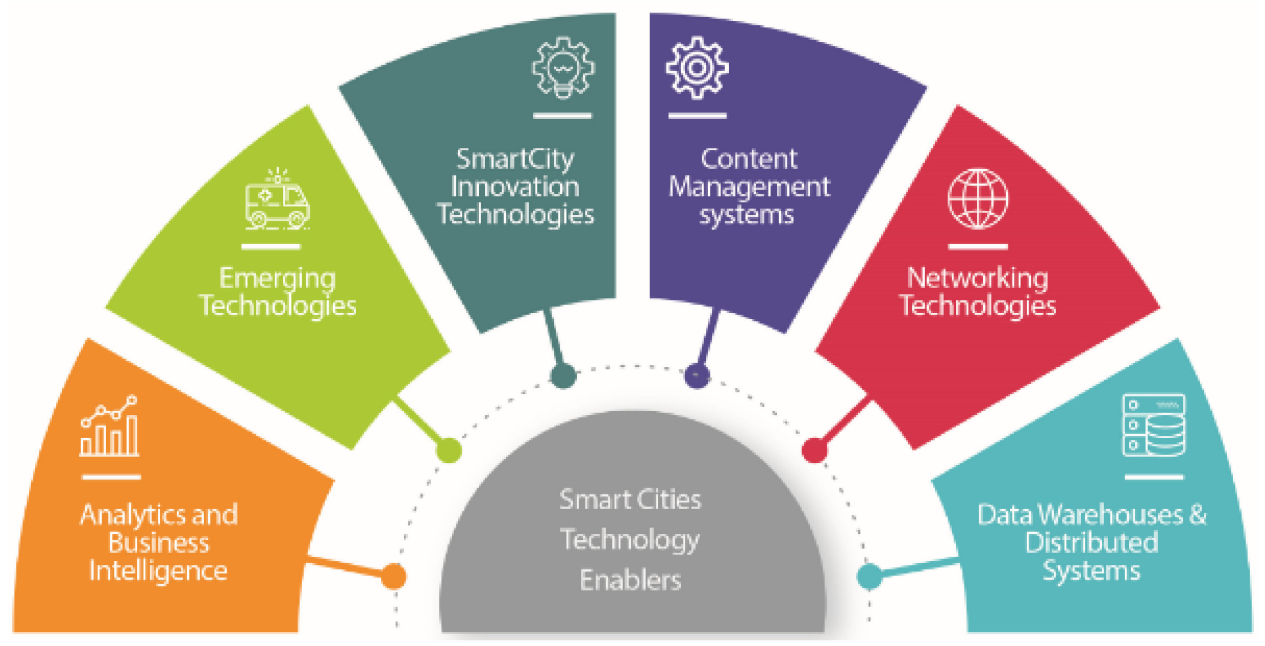

Figure 1. Smart Cities enabling technologies.

The technology landscape is an evolving ecosystem. It is hard to try analyzing it in the context of a static snapshot at a given time. In Figure 2 below, we organized, based on our perceptions and extensive literature review, the key ICTs Technology Clusters of our times that enable and support 
smart cities applications. We do believe that this is a meaningful overview that enables a dialogue for the vision of Smart Cities in our days.

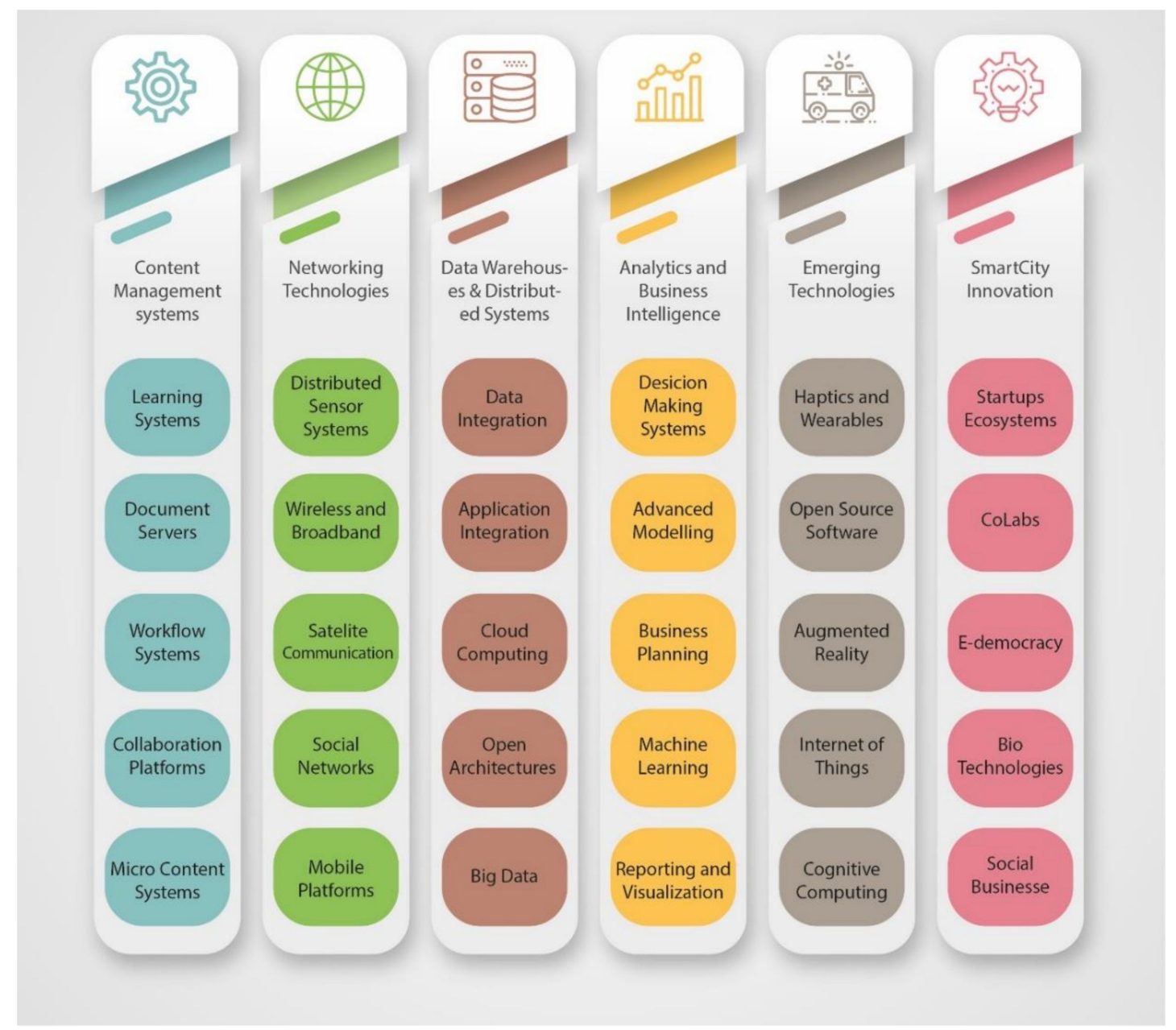

Figure 2. Information and Communication Technology clusters for Sustainable Smart Cities applications (the Authors).

Content Management Systems: The technological cluster of Content Management Systems (CMS) is a diverse and multifaceted domain. In most of the scenarios related to knowledge dissemination, or joint workflow management, CMS is a reliable and efficient technology. Different solutions and applications fall into this category; the dominant ones are those depicted in Figure 2:

- Learning Management Systems (LMS),

- Document Servers,

- Workflow Systems,

- Collaboration Platforms,

- Micro-content Systems.

Networking Technologies: The evolution of Computer Networks technologies and its convergence with Telecommunications was probably one of the most recent influential integrations. Computing and Telecommunications can be seen now as an integrative whole which enriched the user experience with several services and unique experiences permitting innovative thinking on the domain. It seems that there is no limit anymore for the development of channels for the distribution of information.

- $\quad$ Distributed Sensor Networks/Systems (DSN) 
- Wireless and Broadband,

- Satellite Communication,

- Social Networks,

- Mobile Platforms.

Data Warehouses \& Distributed Systems: Our society is a data-driven society. A variety of data are generated, stored and used in different infrastructures and schemas. Additional value is generated by a sophisticated transformation of data to insights. Advanced decision making and managerial support can be performed. One of the greatest challenges of our times is to manage consistent information in a timely and accurate manner. Big Data research is a new paradigm for the processing of data without direct human intervention. Intelligent miners over distributed data frameworks like Hadoop is a new value proposition, http://hadoop.apache.org/

- Data Integration,

- Application Integration,

- Cloud Computing: Cloud,

- Open Architectures,

- Big Data.

Analytics and Business Intelligence

- Decision-Making Systems,

- Advanced Modelling and Business Planning,

- Machine Learning,

- Reporting and Visualization.

Emerging Technologies: The main feature of Technology is its evolution. It is hard for technology to keep for a long time the characterization of innovative. From the other side though, every few years we have technologies that for the first time define a brand-new market. It is just like short innovative circles occurring periodically and the innovation process seems to be a spiral ongoing process with new tools and technologies in the short term. It is also significant to realize that this is not by default a sustainable process. Without a strategic vision for the adoption of technologies especially in a so critical context such as smart cities, unfortunately, we will have many unsuccessful investments with a short beneficiary horizon. The following is an indicative short list of emerging technologies with an estimated great impact for the next years:

- Haptic and Wearables,

- Open Source Software and Open AI,

- Augmented Reality,

- Internet of Things,

- Cognitive Computing.

Within this interesting research context, the evolution of smart cities research requires significant integration of four domains. First of all, it is required to interpret the value contribution of emerging technologies and ICTs in the local social context [21]. The creation of pilot, innovative smart cities eco-systems in the local context promotes the added value of interdisciplinary smart cities research [22]. In another direction [23] the integration of ICTs for the promotion of technology-driven innovation and entrepreneurship imposes the need to understand the social dimension of businesses and to cultivate this culture in the local context. Additionally, the update of the production model and innovations in the agriculture domain and farming [24], links directly smart cities research to critical sustainable development goals. The digitization of services linked to environmental management is also a bold new direction of research [25]. One of the most interesting research dimensions is related to the 
realization of the needs of the digital citizen [26]. In such a diverse and complicated socio-technical research context for smart cities where also behavior and attitudes play a critical role, it is challenging for our research to codify tacit knowledge of smart cities users. We have from the beginning of our effort to state the limitations of our research: The generalization of findings should always take into consideration the social context of our research. The human factor in smart cities research is always the most important factor for interpretation of findings. The same stands for the social construct.

In the next section, we are elaborating on our research model and the key research questions of our study.

\section{Research Methodology and Research Model}

The arguments elaborated in this paper derive from critical analysis of the existing debate on smart cities. These have been enriched by a pilot survey that garnered 102 responses (see Appendix A) from a carefully selected international focus group. The respondents, highly educated individuals, have been selected on the basis of their ability and their propensity to use smart city services. The hypothesis against which the so-constructed focus group was established was that a positive direct correlation exists between respondents' education level and their awareness, ability, and propensity to use smart city services. Drawing from the literature review and critical analysis, a research model was developed (See Figure 3 below) and the questionnaire was constructed. Given the breadth of the questionnaire and the ground the answers covered, the survey and its outcomes offer answers to several research questions. Indeed, this paper adds to our earlier work [2].

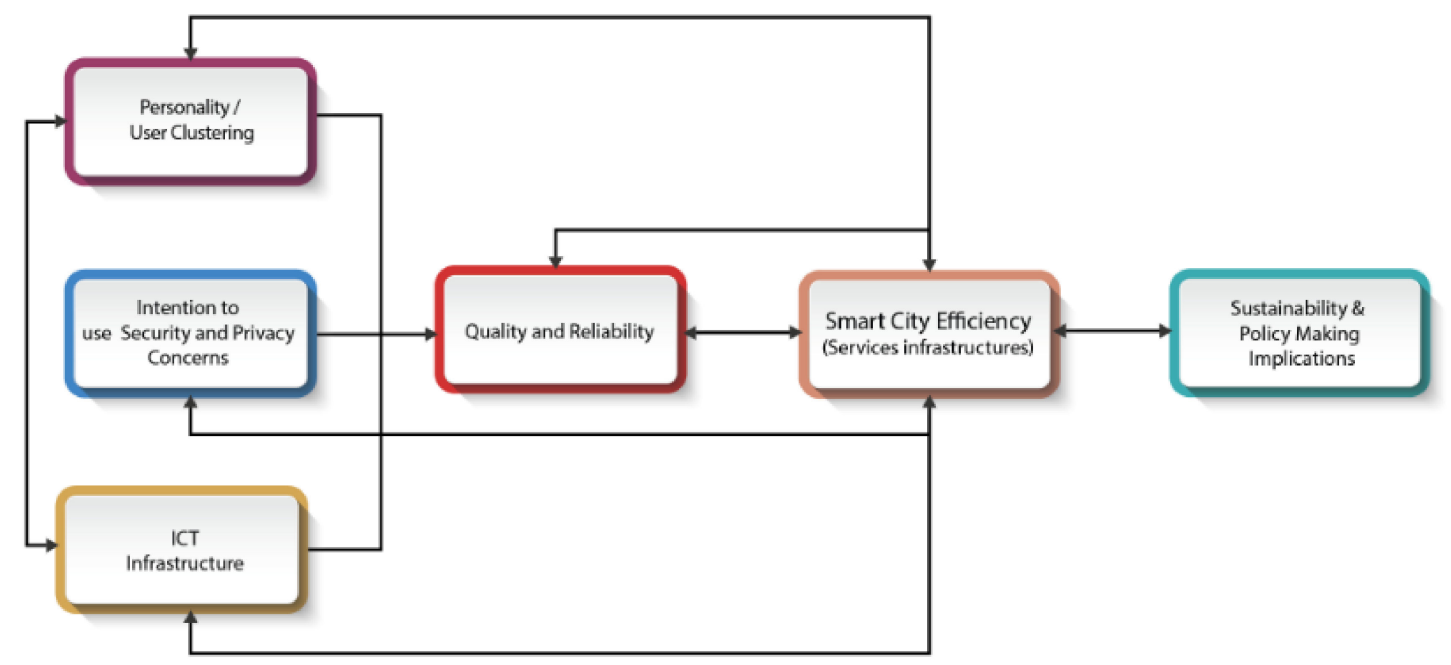

Figure 3. The integrated research model of our study [3].

The discussion in this paper employs findings associated with the following research variables: intention to use smart city services; the existence of enabling ICT infrastructure; quality and reliability of the existing infrastructure; sustainability and policy-making implications. Likert-type questions were developed to measure respondents' perceptions and expectations to relevant issues, constituting respective research variables in this context. These were complemented by an integrated meta-analysis of the responses.

Our research model is an amalgamation of desktop research, quantitative and qualitative research. The stages of our research methodology are summarized as follows (Figure 4):

- Outline the conceptual framework, based on 'the normative bias' of smart cities research thesis [1-3],

- conduct a thorough literature review on ICT-enhanced services in smart cities context,

- devise an outline of existing smart city services,

- establish criteria of categorization of ICT-services, and

- identify clusters of smart city services and elaborate on them. 
In the following move, drawing on the outcomes of a pilot international survey conducted in 2018, [2]

- citizens' perceptions and awareness of smart city services they have access to are examined and - grouped according to the clusters of smart city services' defined earlier.

- Against this backdrop, citizens' perceptions and awareness of smart city services are correlated with vendors', policymakers', businesses' etc., prerogatives in the field of smart city services.

- In this way, in the concluding part, a set of recommendations for respective stakeholders is outlined.

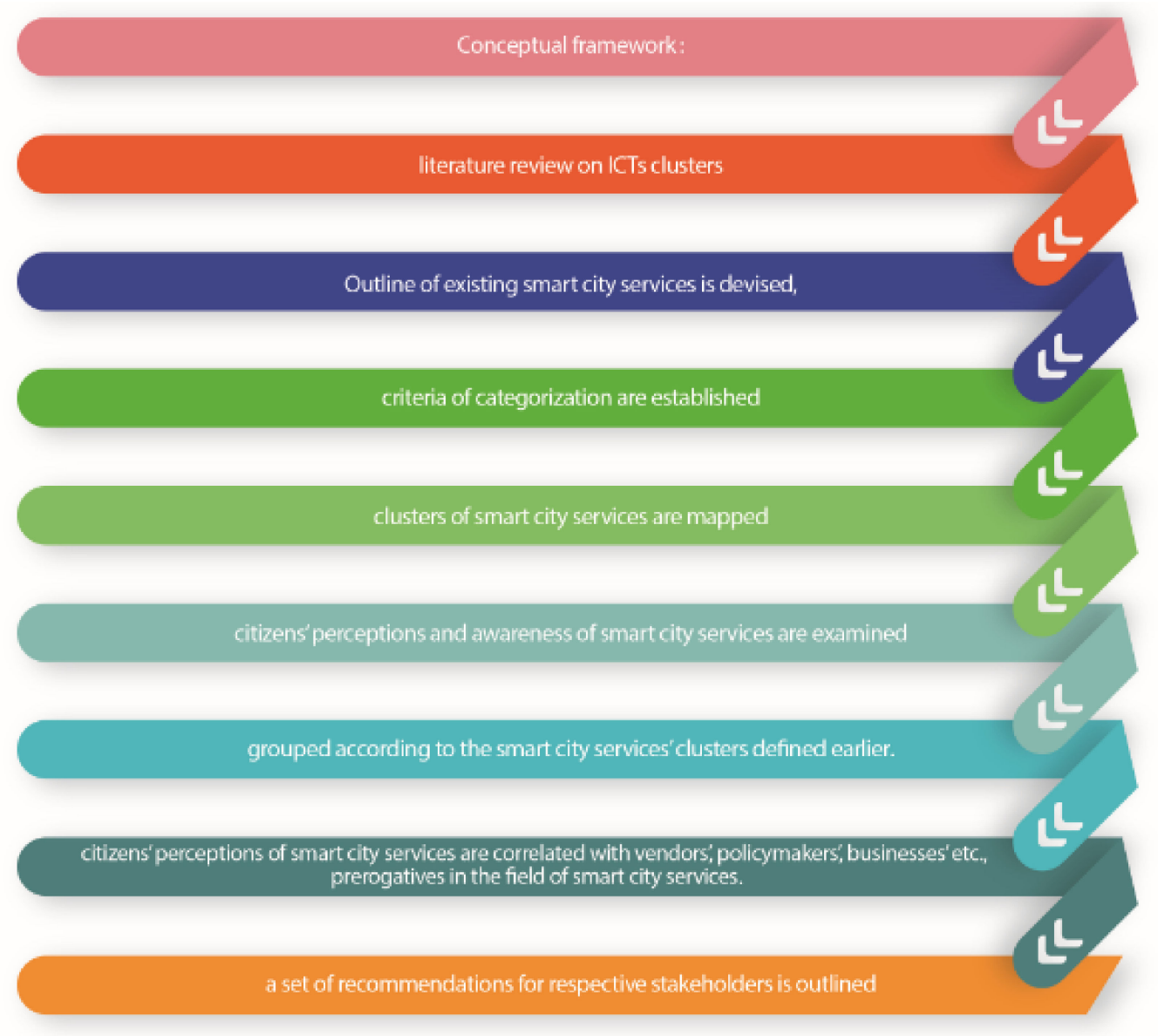

Figure 4. Research Methodology of our study.

The insights, concerns, and considerations inspired by the rich body of literature on smart cities that exists guided the process through which the research objectives of this study were formulated. These included the following questions:

- What are the perceptions of smart city services users for the selective technology-enabled smart cities services and applications?

- Which are the key enabling technologies that are adopted from smart city services users in their daily life?

- What are the interpretations of these perceptions for the design of future smart city services?

- What are the sustainability and policy-making implications of our research?

In the next section, we present the main findings of our research. 


\section{Reading the Outcomes of the Pilot Study}

In our research, we tried to codify the perceptions of smart city users related to seven key clusters of information and communication technologies. (ICT infrastructure in our research model):

1. Content Management Smart cities services and applications

2. Collaboration platforms for Smart cities services and applications

3. Networking Technologies for Smart cities services and applications

4. Data Ware Houses and Distributed Systems for Smart cities services and applications

5. Analytics and Business Intelligence for Smart cities services and applications

6. Emerging Technologies for Smart cities services and applications

7. Smart City Innovation for Smart cities services and applications

For each of these technology clusters, we specified a number of indicative smart cities applications (see Appendix A, for the full set of smart cities services under consideration).

\subsection{Perceptions of Users for Technology Clusters Ratings}

In Figure 5, we present the average rating of users for each of the technology clusters. It is extremely interesting to elaborate on some of the key findings:

- The average rating for the frequent use of diverse technologies for the provision of smart city services is ranging from $34 \%$ to $46 \%$. This, in fact, provides a critical mass of users for smart city services. A question for future research is related to advanced policy-making: what are the required strategies and policies to support people who are concerned by the efficiency of services to adopt and to integrate into their lives.

- A significant part of responders ranging from $19 \%$ to $25 \%$, defines themselves as users of smart cities applications with great motivation to adopt smart cities services, enabled by all the seven clusters of smart cities enabling technologies.

- As a direct interpretation of the above findings, it is evident from our empirical study that almost two-thirds of responders constitute a group of light and heavy smart cities services. In fact, it seems that the adoption of various services in the past years resulted in increased motivation and intention to use smart cities services.

- A significant part of responders is also skeptical about the use of ICTs for smart city services. Based on the findings of our research, this group of people is ranging from $11 \%$ to $13 \%$ of the total population. This is a key finding of our research and for sure, future research should analyze further the qualitative characteristics for their disposition to use smart services. In most of the cases, these are related to privacy and security concerns.

- One more key finding is that content management and networking services have currently the greater number of users with a strong outlook also for use in the near future. 


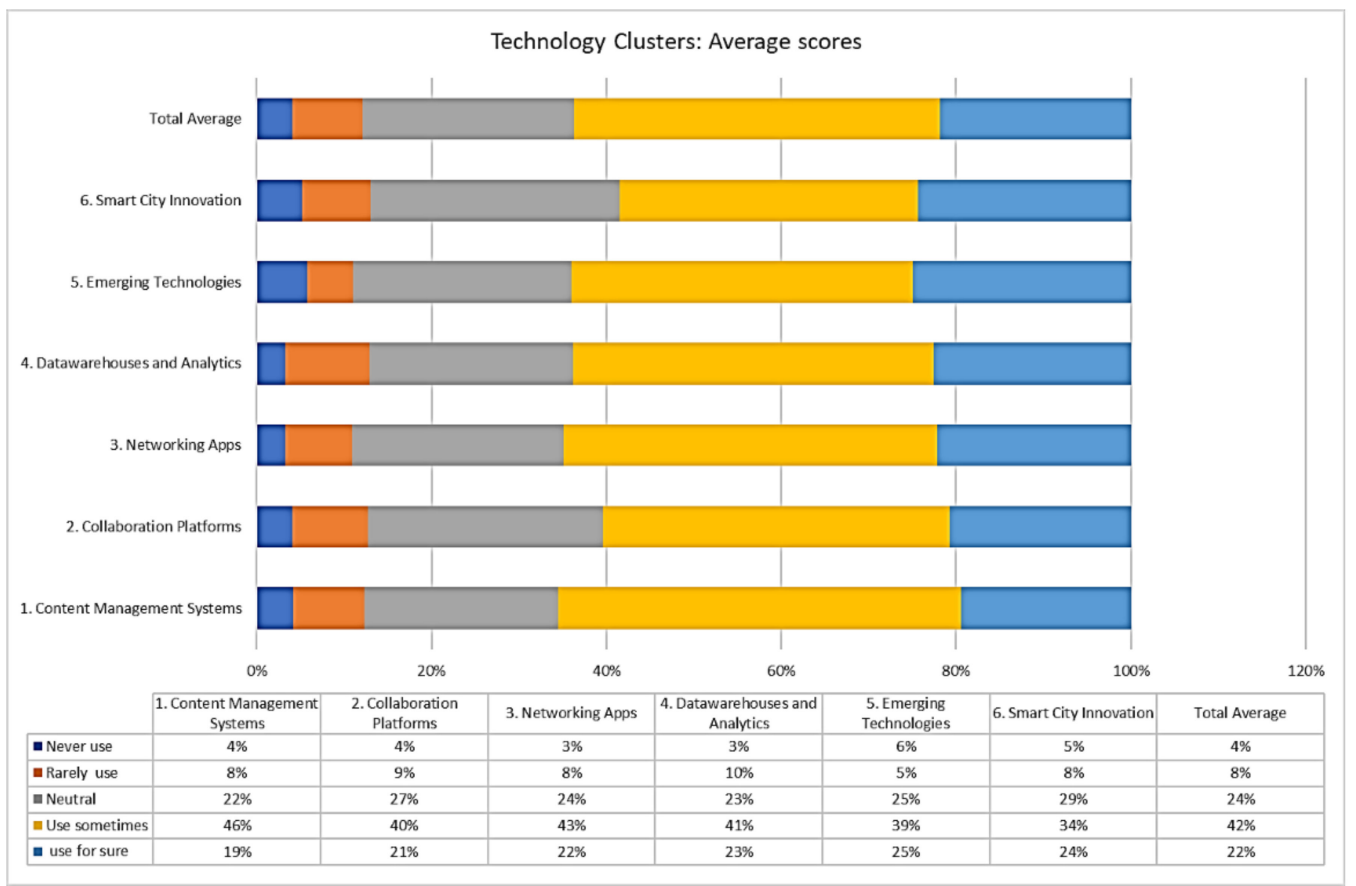

Figure 5. Technology clusters for Sustainable Smart Cities applications: Overview of rating by real users.

\subsection{Perceptions of Users for More Favorable to Use Applications}

In Table 1, below, we summarize the key findings related to the rating of smart cities services. Most of the users seem very happy to use and eager to use in the future a variety of smart cities applications that fall into technology clusters we presented. Given the limitations of our study, for sure, we cannot generalize these results to the global population, but given the characteristics of our sample, these are some interesting findings:

Table 1. More favorable to use smart city applications.

\begin{tabular}{|c|c|}
\hline Indicative Smart City Application & Overall Score \\
\hline $\begin{array}{l}\text { News and insights smart systems related to City Life (perceptions about quality of life, opinions and } \\
\text { ideas for prosperity and response to critical social problems) }\end{array}$ & 3.8 \\
\hline Open educational spaces (integration of Massive Open Online Courses in a simple access point) & 3.8 \\
\hline An advanced cognitive computing-based healthcare system for diagnosis & 3.8 \\
\hline $\begin{array}{l}\text { A global smart urban network connecting research institutions all over the world for the promotion } \\
\text { of a humanistic vision }\end{array}$ & 3.8 \\
\hline A wide area network with distributed scientific committees and ongoing open source projects & 3.8 \\
\hline $\begin{array}{l}\text { The utilization of the smart city infrastructure for the enhancement of youth entrepreneurship or } \\
\text { startups networks }\end{array}$ & 3.8 \\
\hline $\begin{array}{l}\text { An Augmented Reality (AR) application in the historical centers of World Capitals enabling access } \\
\text { to immersive scenarios of content explorations }\end{array}$ & 3.7 \\
\hline $\begin{array}{l}\text { The design of an Innovation hub, where innovators, individual or businesses, industrial partners } \\
\text { and funding organization collaborate to build joint alliances }\end{array}$ & 3.7 \\
\hline A transparent ecosystem of open and distributed, publicly accessible analytics & 3.7 \\
\hline $\begin{array}{l}\text { A big data platform for managing inquiries over medical data, for example, automatic planning of } \\
\text { medical appointments or services supervising cost control in health expenditures are } \\
\text { interesting applications }\end{array}$ & 3.7 \\
\hline Smart Urban applications for digital signatures issuing over distributed documents & 3.7 \\
\hline $\begin{array}{l}\text { An advanced Question and Answering System with collaborative filtering and } \\
\text { automatic suggestions }\end{array}$ & 3.7 \\
\hline $\begin{array}{l}\text { A volunteer-based scientific collaborative space with the provision of open projects for participation } \\
\text { and delegation }\end{array}$ & 3.7 \\
\hline
\end{tabular}


- A number of responders, holding a Ph.D., are looking for trusted news and insights systems, related to City Life. There is a well-defined market of citizens that are interested in this category of content. Diverse technologies and systems can support such an application.

- There is a high demand for open educational spaces, and one-stop-access learning services in the context of a smart city. The majority of the respondents of our survey indicated that the support of training and learning is a key aspect of a smart cities infrastructure.

- There is a high interest in research collaboration enhancement through services that promote international collaboration and group competencies.

- Users are also interested in applications for the provision of collaborative spaces for start-up ecosystems and the enhancement of entrepreneurship.

- Special interest also citizens show for services and applications that promote cultural and historical heritage in an integrated way.

- In the top priorities of users also is the case of digital signatures which allows flexible, dynamic and real-time services.

\subsection{Top 13 Services in Favorable Use_-Intention to Use}

In Table 2, we also summarize the top 13 services based on the perceptions of participants in our survey. While for sure the generalization of findings has limitations, the responses are indicative and highlight a strong trend: users are interested in trusted news related to the city, are eager to enjoy high-quality healthcare smart services, and also look for innovation and enhanced education and training. E-democracy platforms and services, as well as an application for the promotion of trusted business, innovation and entrepreneurship through research collaboration, are highlighted.

Table 2. More favorable to use smart city services per cluster.

\begin{tabular}{|c|c|c|c|c|}
\hline ICT Cluster & Services & -USE & +USE & Favorable+ \\
\hline 1. CMS & $\begin{array}{l}\text { News and insights smart systems related to City Life } \\
\text { (perceptions about quality of life, opinions and ideas for } \\
\text { prosperity and response to critical social problems) }\end{array}$ & $21 \%$ & $79 \%$ & $58 \%$ \\
\hline 3. NETWORKING & $\begin{array}{l}\text { An advanced cognitive computing-based healthcare system } \\
\text { for diagnosis }\end{array}$ & $26 \%$ & $74 \%$ & $48 \%$ \\
\hline 4. DW & $\begin{array}{l}\text { The design of an Innovation hub, where innovators, } \\
\text { individual or businesses, industrial partners and funding } \\
\text { organization collaborate to build joint alliances }\end{array}$ & $27 \%$ & $73 \%$ & $45 \%$ \\
\hline 1. CMS & $\begin{array}{l}\text { Open educational spaces (integration of Massive Open Online } \\
\text { Courses in a simple access point) }\end{array}$ & $28 \%$ & $72 \%$ & $44 \%$ \\
\hline 5. Emerging Techs & $\begin{array}{l}\text { An Augmented Reality (AR) application in the historical } \\
\text { centers of World Capitals enabling access to immersive } \\
\text { scenarios of content explorations }\end{array}$ & $28 \%$ & $72 \%$ & $44 \%$ \\
\hline 1. CMS & $\begin{array}{l}\text { Smart Urban applications for digital signatures issuing over } \\
\text { distributed documents }\end{array}$ & $28 \%$ & $72 \%$ & $43 \%$ \\
\hline 3. NETWORKING & $\begin{array}{l}\text { A global smart urban network connecting research institutions } \\
\text { all over the world for the promotion of a humanistic vision }\end{array}$ & $28 \%$ & $72 \%$ & $43 \%$ \\
\hline 3. NETWORKING & $\begin{array}{l}\text { A wide area network with distributed scientific committees } \\
\text { and ongoing open source projects }\end{array}$ & $28 \%$ & $72 \%$ & $43 \%$ \\
\hline 1. CMS & $\begin{array}{l}\text { Governmental platform for discussion on planned reforms } \\
\text { and feedback management }\end{array}$ & $29 \%$ & $71 \%$ & $42 \%$ \\
\hline 4. DW & $\begin{array}{l}\text { A transparent ecosystem of open and distributed, publicly } \\
\text { accessible analytics }\end{array}$ & $30 \%$ & $70 \%$ & $40 \%$ \\
\hline 4. DW & $\begin{array}{l}\text { The utilization of the smart city infrastructure for the } \\
\text { enhancement of youth entrepreneurship or start-ups networks }\end{array}$ & $31 \%$ & $69 \%$ & $38 \%$ \\
\hline 3. NETWORKING & $\begin{array}{l}\text { A volunteer-based scientific collaborative space with the } \\
\text { provision of open projects for participation and delegation }\end{array}$ & $32 \%$ & $68 \%$ & $36 \%$ \\
\hline 2. COLLABORATION & $\begin{array}{l}\text { An advanced Question and Answering System with } \\
\text { collaborative filtering and automatic suggestions }\end{array}$ & $33 \%$ & $67 \%$ & $35 \%$ \\
\hline
\end{tabular}




\subsection{Less Favorable to Use/Intention to Use Smart City Services}

In this section, it is quite interesting to realize also some services that many users would not be happy to use, based on their value perception or consideration of security, privacy etc. In Table 3, below you can find an overview.

Table 3. Less favorable to use smart city services per cluster.

\begin{tabular}{|c|c|c|c|c|}
\hline ICT cluster & Services & -USE & + +USE & Favorable+ \\
\hline 4. DW & $\begin{array}{l}\text { A business miner/insider of social opinions and beliefs through } \\
\text { rating mechanisms of business services and quality of } \\
\text { customer support }\end{array}$ & $37 \%$ & $63 \%$ & $25 \%$ \\
\hline 3. NETWORKING & An integrated complains management system over social networks & $38 \%$ & $62 \%$ & $24 \%$ \\
\hline 4. DW & $\begin{array}{l}\text { A cloud-based, system for accessing and expanding the } \\
\text { smart services }\end{array}$ & $38 \%$ & $62 \%$ & $24 \%$ \\
\hline 1. CMS & Social campaigns management run by active citizens & $38 \%$ & $62 \%$ & $23 \%$ \\
\hline 2. COLLABORATION & $\begin{array}{l}\text { Open shared collaborative spaces for communities of practice in the } \\
\text { context of smart cities }\end{array}$ & $38 \%$ & $62 \%$ & $23 \%$ \\
\hline 5. Emerging Techs & $\begin{array}{l}\text { A smart mobile application capable or recommending news alerts } \\
\text { to citizens based on their opinions as they are expressed in } \\
\text { social media }\end{array}$ & $39 \%$ & $61 \%$ & $23 \%$ \\
\hline 4. DW & $\begin{array}{l}\text { Advanced notification services for status changes related to the } \\
\text { human activity }\end{array}$ & $39 \%$ & $61 \%$ & $22 \%$ \\
\hline 4. DW & $\begin{array}{l}\text { A Value adding service between Smart Cities networks } \\
\text { (e.g., the Smart City Lighthouses projects in Europe) }\end{array}$ & $39 \%$ & $61 \%$ & $22 \%$ \\
\hline 5. Emerging Techs & $\begin{array}{l}\text { An advanced accessibility application capable of customizing the } \\
\text { interface of smart applications to disabled people }\end{array}$ & $39 \%$ & $61 \%$ & $22 \%$ \\
\hline 2. COLLABORATION & $\begin{array}{l}\text { An advanced visualization system for analytics related to } \\
\text { individual and group performances in the smart city }\end{array}$ & $39 \%$ & $61 \%$ & $21 \%$ \\
\hline 6. Smart City Innovation & $\begin{array}{l}\text { An application where citizens and other stakeholders vision the } \\
\text { City of } 2050 \text { or City of } 2060 \text { are good initiatives for minds and } \\
\text { creativity. The collective wisdom should be exploited for } \\
\text { good purposes }\end{array}$ & $40 \%$ & $60 \%$ & $20 \%$ \\
\hline 3. NETWORKING & $\begin{array}{l}\text { A peer to peer application like MyCitySmartConnect for } \\
\text { smartphones enabling the effective sharing of files, as well as } \\
\text { opinions, ideas, etc. }\end{array}$ & $40 \%$ & $60 \%$ & $20 \%$ \\
\hline 2. COLLABORATION & $\begin{array}{l}\text { An automated message exchanging system between different } \\
\text { authorities and organizations in the smart city context, for } \\
\text { automating the workflow of distributed processes affecting citizens } \\
\text { perceptions about service and support }\end{array}$ & $41 \%$ & $59 \%$ & $18 \%$ \\
\hline 5. Emerging Techs & $\begin{array}{l}\text { An integrated system of Audio Sensors in urban areas detecting the } \\
\text { noise and customizing policies for its management and protection } \\
\text { of urban areas }\end{array}$ & $41 \%$ & $59 \%$ & $18 \%$ \\
\hline 6. Smart City Innovation & $\begin{array}{l}\text { A smart application that brings together the most talented people in } \\
\text { a city and through the exchange of ideas and joint efforts they } \\
\text { design new services innovations and systems }\end{array}$ & $42 \%$ & $58 \%$ & $17 \%$ \\
\hline 3. NETWORKING & $\begin{array}{l}\text { A mobile application aiming to aggregate personal contributions } \\
\text { about museum exhibits }\end{array}$ & $42 \%$ & $58 \%$ & $16 \%$ \\
\hline 1. CMS & $\begin{array}{l}\text { A Smart City MOOCs system integrated with social mining } \\
\text { capabilities and analytics }\end{array}$ & $42 \%$ & $58 \%$ & $15 \%$ \\
\hline 3. NETWORKING & $\begin{array}{l}\text { A supervising system for the dynamic allocation of network } \\
\text { resources to different applications run in the smart urban design } \\
\text { can secure an excellent quality of services }\end{array}$ & $43 \%$ & $57 \%$ & $15 \%$ \\
\hline 4. DW & Open Architectures for community-based problem solving & $43 \%$ & $57 \%$ & $15 \%$ \\
\hline 6. Smart City Innovation & $\begin{array}{l}\text { An open dialogue platform that for the same problem aggregates } \\
\text { the propositions of different scientific or social communities }\end{array}$ & $43 \%$ & $57 \%$ & $14 \%$ \\
\hline 1. CMS & $\begin{array}{l}\text { Customized smart city tollbars over browsers ("LoveMyCity") and } \\
\text { rating systems to local services or resources in an urban territory }\end{array}$ & $43 \%$ & $57 \%$ & $13 \%$ \\
\hline 1. CMS & Smart Services against victimization and harassment etc. & $46 \%$ & $54 \%$ & $8 \%$ \\
\hline 4. DW & Rating Systems over Big Data & $50 \%$ & $50 \%$ & $1 \%$ \\
\hline 2. COLLABORATION & An automatic video annotator of Smart City executive meetings & $53 \%$ & $47 \%$ & $-6 \%$ \\
\hline
\end{tabular}




\section{Discussion and Conclusions}

The objective of this paper was to explore the link between end-users' perceptions and expectations regarding smart city services to the industry's (broadly defined) awareness and capacity to respond to citizens' needs and expectations. Some of the key findings outlined in this research are as follows:

- Citizens show different perceptions of different types of services. Most of them are willing to use smart city services that promote them trusted news from local communities, access to learning and training resources plus services that promote innovation and entrepreneurship at a global scale.

- The average rating for the frequent use of diverse technologies for the provision of smart city services is ranging from $34 \%$ to $46 \%$. This, in fact, provides a critical mass of users for smart city services.

- A question for future research is related to advanced policy-making: what are the strategies and policies that should be developed to alleviate end-users' concerns regarding the efficiency and credibility of ICT-enhanced services in city/urban space? How to ensure that the existing services add value to citizens lives?

- A significant part of responders ranging from $19 \%$ to $25 \%$, defines themselves as have a user of smart cities applications with great motivation to adopt smart cities services, enabled by all the seven clusters of smart cities enabling technologies.

- As a direct interpretation of the above findings, it is evident from our empirical study that almost two-thirds of responders constitute a group of light and heavy smart cities services. In fact, it seems that the adoption of various services in the past years resulted in increased motivation and intention to use smart cities services.

- There are still well-educated people that are really concerned about the use of smart cities services and application. Based on the findings of our research, this group of people is ranging from $11 \%$ to $13 \%$ of the total population. This is a key finding of our research and for sure, future research should analyze further the qualitative characteristics for their disposition to use smart services. In most of the cases, these are related to privacy and security concerns.

- One more key finding is that content management and networking services have currently the greater number of users with a strong outlook also for use in the near future.

- Users are looking for trusted news and insights systems, related to city life. There is a well-defined market of citizens that are interested in this category of content. Diverse technologies and systems can support such an application.

- There is a high demand for open educational spaces, and one-stop-access learning services in the context of a smart city. The majority of the respondents of our survey indicated that the support of training and learning is a key aspect of a smart cities' infrastructure.

- There is a high interest in research collaboration enhancement through services that promote international collaboration and group competencies.

- Users are also interested in applications for the provision of collaborative spaces for start-up ecosystems and the enhancement of entrepreneurship.

- Special interest also citizens show for services and applications that promote cultural and historical heritage in an integrated way.

- In the top priorities of users also is the case of digital signatures which allows flexible, dynamic and real-time services.

- Users are interested in trusted news related to the city, they are eager to enjoy high-quality healthcare smart services and also look for innovation and enhanced education and training. E-democracy platforms and services, as well as an application for the promotion of trusted business, innovation and entrepreneurship through research collaboration, are highlighted.

One of the key purposes of our study is to link end-users' perceptions and expectations with industry's response [3]. As a critical interpretation of these key findings or our research, given the limitations, we have to comment on the following: 
1. Our finding supports somehow, or it is an indication that the argumentation provided by Hollands [19], that "Driven by the profit motive of global high-technology companies, in collusion with the trend towards city governance being wedded to a competitive form of "urban entrepreneurialism', has left little room for ordinary people to participate in the smart city". A critical number of responders in our study highlighted their concerns and their limited motivation to be parts of smart cities services mostly concerned about privacy, security and trust of ICT-enabled platforms. Based on propositions of Hollands that a key response to the weak performance of the dominant normative bias of ICT's experts and industry partners related to the effectiveness of smart city services, a radical shift in smart cities research concerns considering smartness from different perspectives emanating from small-scale and fledgling examples of participatory and citizen-based types of smart initiatives. This is a bold finding that needs to be interpreted by Industry players and Industrial partners in Smart Cities Services Domain.

2. In close relation to the ideas and opinions expressed by Sennett [20] in "No one likes a city that's too smart", it is extremely interesting to realize that the responders of our survey ranked in the top priorities services that keep technology in the "background" and leave the space for creativity, peer matching, dialogue, research collaboration, skills, and competencies building. For example smart cities services like the ones highlighted in our study "News and insights smart systems related to City Life (perceptions about quality of life, opinions and ideas for prosperity and response to critical social problems)", "Open educational spaces (integration of Massive Open Online Courses in a simple access point", "A global smart urban network connecting research institutions all over the world for the promotion of a humanistic vision", "A wide area network with distributed scientific committees and ongoing open source projects", "The utilization of the smart city infrastructure for the enhancement of youth entrepreneurship or startups networks" show that the smart cities research moves to a new level of maturity where advanced technologies provided by Industry matter only if they facilitate real human needs related to social networking for value-adding purposes.

3. A third significant finding and interpretation for the industry is the reality that most of the users of smart cities services seem to don't care for the sophistication of smart cities infrastructures and services. In a way, they consider technology as a "black box" where the complexity of computing approach does not matter for real users. This is a direct indication that sets design guidelines to Industry providers of smart cities services that the "human" factor matters more than the technology component.

4. An indirect interpretation of our study is also that Industry leaders and providers should adopt user perceptions analysis and studies in a wider context, depth, and breath. Our study was only a pilot study in which the generalization of findings needs to be done considering the social context of our research. Nevertheless, though some key findings provide significant insights that the future of smart cities research needs at least four critical components:

a. Openness in the meaning of open participatory communities

b. A balanced approach in terms of the social and technology components

c. Trust, in terms of transparency of services, data protection, and privacy and authentication

d. Integration, in the sense of complete, end-to-end user/citizen experiences

5. A direction for combined industrial and academic research must be in the same line with this pilot research. Given the billions that are spent worldwide for Smart Cities services and application, it is strategic to anchor investments in direct interpretations of user perceptions

6. From a sustainability point of view, it is critical to continue the debate about how social inclusive economic growth and open democracy can be facilitated by Smart Cities applications.

Author Contributions: M.D.L., A.S. and A.V. contributed equally to the design, implementation, conduct of research and analysis of data and the delivery of the main findings. All co-authors contributed equally to all phases of this research. 
Acknowledgments: The authors would like to thank Effat University in Jeddah, Saudi Arabia for funding the research reported in this paper through the Research and Consultancy Institute.

Conflicts of Interest: The authors declare no conflict of interest.

\title{
Appendix A Our Research Tool
}

\author{
Smart City Technologies
}

\section{Content Management Smart Urban Systems Cluster}

- Open educational spaces (integration of Massive Open Online Courses in a simple access point)

- The Smart Open University as an open space of dialogue

- A Smart City MOOCs system integrated with social mining capabilities and analytics

- Social campaigns management run by active citizens

- A Smart Urban Learning Management System for Entrepreneurs

- A Smart system of Social Inclusion, Diversity and Equality

- Smart Services against victimization and harassment etc.

\section{Smart City Document Management Systems Cluster}

- Smart Urban applications for digital signatures issuing over distributed documents

- Advanced voice navigation and narration systems over published documents and websites in Smart City Context for advanced accessibility

- Smart wikis hub for ideas, opinion, and social mining.

- News and insights smart systems related to City Life (perceptions about quality of life, opinions and ideas for prosperity and response to critical social problems)

- Sophisticated content annotators for citizens public comments and shared ideas

- Customized smart city toolbars over browsers ("LoveMyCity") and rating systems to local services or resources in urban territory.

- A collaborative community-driven vocabulary, taxonomy and annotation schema for smart city services

- Supervising systems of systems capable of aggregating and routing all relevant documents across distributed procedures.

- Documents as web services in a smart city context

- A marketplace of smart documents

- An integrated Information System for smart city administrators, policymakers a d computer engineers, for workflow modeling towards new smart city services and prototype systems generation

\section{Smart City Micro-content Services and Systems}

- Governmental platform for discussion on planned reforms and feedback management.

- Advanced participatory democracy applications for the dynamic aggregations of converging opinions, groupings based on beliefs etc.

- Smart urban application for summarizing trending opinions and feeling of citizens related to their quality of living, or complaints they might have from local authorities.

- A supervising application for distribution blocking of fake news and a related toolbar helping the member of the smart urban design to tag news as fake and thus preventing others from harm.

- A fully annotated, searchable ecosystem of cultural blogs promoting the exciting things that happen in the city.

- Social networks of collaborating artists, or citizens promoting open art

- Automatic translation system with voice navigation to the cultural context 
- Chatbots as a smart city assistant (e.g., a chat bot that provides support to citizens requesting the issuing of a digital certificate)

\section{Smart City Collaboration Systems and Services}

- A smart requests' aggregator application for flexible response to citizens inquiries.

- An advanced Question and Answering System with collaborative filtering and automatic suggestions

- An automated message exchanging system between different authorities and organizations in the smart city context, for automating the workflow of distributed processes affecting citizens perceptions about service and support.

- A school is driven peer-to-peer collaboration system for the development of meaningful learning stories over shared cultural content.

- A smart ontology annotation system, that scans the entire minutes of meetings in Mayor Hall Meetings and permits citizens to extract or the public interventions of a member of City Council.

- An automatic video annotator of Smart City executive meetings

- An advanced visualization system for analytics related to individual and group performances in the smart city.

- Advanced visualizations of smart city neighborhood social networks

- A visual interactive system for navigating to documents archives in smart urban designs.

- Open shared collaborative spaces for communities of practice in the context of smart cities.

- A system of systems interface that integrates through APIs public discussions in social media and constructs automatically consultation documents about critical social issues.

- An intelligent matching collaboration service that brings together groups based on their expertise or capacities for promoting greater collaboration.

- Aa micro-spatial application that enables the exchange of messages between people in the same neighborhood.

- An integrated complains management system over social networks.

- An automatic service selection system based on workflow automation

- A global smart urban network connecting research institutions all over the world for the promotion of a humanistic vision.

\section{Networking Technologies for Smart Urban Systems Cluster}

- A hotspot for micropayments or crowdfunding for smart services sustainability

- A peer-to-peer networking service for activism or open dialogue.

- An advanced networking system for the integration of patient records and advanced data mining value adding services

- An advanced cognitive computing-based healthcare system for diagnosis.

- A wide area network with distributed scientific committees and ongoing open source projects

- A volunteer-based scientific collaborative space with the provision of open projects for participation and delegation.

- A mobile application aiming to aggregate personal contributions about museum exhibits

- A supervising smart city system building dynamically profiles of citizens based on their interaction with several other value-adding systems related to their daily life and interaction with all the types of activities and services offered in the context of the smart city.

- A peer to peer application like MyCitySmartConnect for smartphones enabling the effective sharing of files, as well as opinions, ideas, etc.

- A supervising system for the dynamic allocation of network resources to different applications run in the smart urban design can secure an excellent quality of services.

Data Ware Houses and Distributed Systems for Smart Urban Applications 
- A semi-automatic annotator of citizens records with a wide-spread scan of all the dispersed databases as a first basis for integration.

- Advanced notification services for status changes related to human activity

- A communication mechanism powered by Semantic Web Technologies aiming to orchestrate the integration of the various data marts with ontologies annotation.

- A big data platform for managing inquiries over medical data, for example, automatic planning of medical appointments or services supervising cost control in health expenditures are interesting applications.

- An Open Educational Big Data Archive of learning resources

- A business miner/insider of social opinions and beliefs through rating mechanisms of business services and quality of customer support.

- Open Architectures for community-based problem solving,

- Open Social Networking for collaboration.

- A smart city integral hub for businesses listing and collaboration

- The design of an Innovation hub, where innovators, individual or businesses, industrial partners and funding organization collaborate to build joint alliances.

- E-Marketplaces of skills and competencies dedicated to promoting the human capital of smart cities,

- E-marketplaces dedicated to local products, cultural artifacts or e-marketplaces related to the exchange economy of social business and entrepreneurship at a local or global scale.

- A secure payment service that can be used by any member of the smart city on demand for the design of export activity.

- A Value adding service between Smart Cities networks (e.g., the Smart City Lighthouses projects in Europe).

- The utilization of the smart city infrastructure for the enhancement of youth entrepreneurship or startups networks.

- $\quad$ Rating Systems over Big Data

- A cloud-based, a system for accessing and expanding the smart services

Analytics and Business Intelligence Smart Urban Systems Cluster

- A transparent ecosystem of open and distributed, publicly accessible analytics

- An application capable of visualizing profile elements not related to explicit knowledge, like beliefs, opinions and calculating the distance between citizens in terms of their personalities would be a case for this cluster.

- A recommender system promoting peers for potential collaboration for joint entrepreneurship.

- A system capable of integrating smart regions urban designs can serve as a hub of collaboration and prosperity.

\section{Emerging Technologies Smart Urban Systems Cluster}

- An Augmented Reality (AR) application in the historical centers of World Capitals enabling access to immersive scenarios of content explorations.

- An AR system supporting a Smart City Schools Distributed Open Laboratory of Life Sciences.

- An advanced accessibility application capable of customizing the interface of smart applications to disabled people

- A smart mobile application capable or recommending news alerts to citizens based on their opinions as they are expressed in social media.

- An open source coding lab for young students

- A Virtual Reality Laboratory System for advanced services e.g., realization of Prototypes of Services, Designs of User Experiences for Smart City Interaction. 
- A Robotics Lab where showcases and experimentations can take place.

- An integrated system of Audio Sensors in urban areas detecting the noise and customizing policies for its management and protection of urban areas.

- An advanced sensor system with cameras and cognitive capabilities alarming authorities for abnormal behavior.

- An advanced IoT service for the fleet management of vehicles in smart urban designs for cost utilization and monitoring.

\section{Smart City Innovation-Smart Urban Systems Cluster}

- A smart application that brings together the most talented people in a city and through the exchange of ideas and joint efforts they design new services innovations and systems.

- An open dialogue platform that for the same problem aggregates the propositions of different scientific or social communities.

- An application where citizens and other stakeholders vision the City of 2050 or City of 2060 are good initiatives for minds and creativity. The collective wisdom should be exploited for good purposes.

\section{References}

1. Visvizi, A.; Lytras, M.D. Rescaling and refocusing smart cities research: From mega cities to smart villages. J. Sci. Technol. Policy Manag. 2018. [CrossRef]

2. Lytras, M.D.; Visvizi, A. Who Uses Smart City Services and What to Make of It: Toward Interdisciplinary Smart Cities Research. Sustainability 2018, 10, 1998. [CrossRef]

3. Visvizi, A.; Lytras, M.D. It's Not a Fad: Smart Cities and Smart Villages Research in European and Global Contexts. Sustainability 2018, 10, 2727. [CrossRef]

4. Datta, A. New urban utopias of postcolonial India: 'Entrepreneurial urbanization' in Dholera smart city, Gujarat. Dialogues Hum. Geogr. 2015, 5, 3-22. [CrossRef]

5. Marvin, S.; Luque-Ayala, A.; McFarlane, C. (Eds.) Smart Urbanism. Utopian Vision or False Dawn? Routledge: London, UK; New York, NY, USA, 2015.

6. Kitchin, R. Making sense of smart cities: Addressing present shortcomings. Camb. J. Reg. Econ. Soc. 2015, 8, 131-136. [CrossRef]

7. Lytras, M.D.; Raghavan, V.; Damiani, E. Big data and data analytics research: From metaphors to value space for collective wisdom in human decision making and smart machines. Int. J. Semant. Web Inf. Syst. 2017, 13, 1-10. [CrossRef]

8. Lytras, M.D.; Mathkour, H.I.; Abdalla, H.; Al-Halabi, W.; Yanez-Marquez, C.; Siqueira, S.W.M. Enabling technologies and business infrastructures for next-generation social media: Big data, cloud computing, internet of things and virtual reality. J. Univ. Comput. Sci. 2015, 21, 1379-1384.

9. Lytras, M.D.; Mathkour, H.I.; Abdalla, H.; Al-Halabi, W.; Yanez-Marquez, C.; Siqueira, S.W.M. An emerging-Social and emerging computing enabled philosophical paradigm for collaborative learning systems: Toward high effective next-generation learning systems for the knowledge society. Comput. Hum. Behav. 2015, 5, 557-561. [CrossRef]

10. Mora-Cantallops, M.; Sánchez-Alonso, S.; Visvizi, A. The influence of external political events on social networks: The case of the Brexit Twitter Network. J. Ambient. Intell. Human. Comput. 2019. [CrossRef]

11. Angelidou, M.; Psaltoglou, A.; Komninos, N.; Kakderi, C.; Tsarchopoulos, P.; Panori, A. Enhancing sustainable urban development through smart city applications. J. Sci. Technol. Policy Manag. 2017. [CrossRef]

12. Lytras, M.D.; Mathkour, H.; Torres-Ruiz, M. Innovative Mobile Information Systems: Insights from Gulf Cooperation Countries and All over the World. Mob. Inf. Syst. 2016, 2016, 2439389. [CrossRef]

13. Keim, D.A. Visual exploration of large data sets. Commun. ACM 2001, 44, 38-44. [CrossRef]

14. Höjer, M.; Wangel, J. Smart sustainable cities: Definition and challenges. Adv. Intell. Syst. Comput. 2014, 310, 333-349.

15. Bi, S.; Liu, Z.; Usman, K. The influence of online information on investing decisions of reward-based crowdfunding. J. Bus. Res. 2017, 71, 10-18. [CrossRef] 
16. Yin, C.; Xiong, Z.; Chen, H.; Wang, J.; Cooper, D.; David, B. A literature survey on smart cities. Sci. China Inf. Sci. 2015, 58, 1-18. [CrossRef]

17. Bibri, S.E.; Krogstie, J. On the social shaping dimensions of smart sustainable cities: A study in science, technology, and society. Sustain. Cities Soc. 2017, 29, 219-246. [CrossRef]

18. Van de Voorde, T.; Jacquet, W.; Canters, F. Mapping form and function in urban areas: An approach based on urban metrics and continuous impervious surface data. Landsc. Urban Plan. 2011, 102, 143-155. [CrossRef]

19. Hollands, R.G. Critical interventions into the corporate smart city. Camb. J. Reg. Econ. Soc. 2015, 8, 61-77. [CrossRef]

20. Sennett, R. No One Likes a City That's Too Smart, The Guardian, 4 December 2012. Available online: http:/ / www.guardian.co.uk/commentisfree/2012/dec/04/smart-city-rio-songdo-masdar (accessed on 16 February 2019).

21. Wolski, O.; Wójcik, M. Smart villages revisited: Conceptual background and new challenges at the local level. In Smart Villages in the EU and Beyond; Visvizi, A., Lytras, M.D., Mudri, G., Eds.; Emerald Publishing: Bingley, UK, 2019; ISBN 9781787698468.

22. Bibri, S.E. On the sustainability of smart and smarter cities in the era of big data: An interdisciplinary and transdisciplinary literature review. J. Big Data 2019, 6, 25. [CrossRef]

23. Klopp, J.; Petretta, D. The urban sustainable development goal: Indicators, complexity and the politics of measuring cities. Cities 2017, 63, 92-97. [CrossRef]

24. Azevedo, D. Precision agriculture and the smart village concept. In Smart Villages in the EU and Beyond; Visvizi, A., Lytras, M.D., Mudri, G., Eds.; Emerald Publishing: Bingley, UK, 2019; ISBN 9781787698468.

25. Albino, V.; Berardi, U.; Dangelico, R.M. Smart Cities: Definitions, Dimensions, Performance, and Initiatives. J. Urban Technol. 2015, 22, 3-21. [CrossRef]

26. Cardullo, P.; Kitchin, R. Smart urbanism and smart citizenship: The neoliberal logic of 'citizen-focused' smart cities in Europe. Environ. Plann. C: Polit. Space 2018. [CrossRef]

(C) 2019 by the authors. Licensee MDPI, Basel, Switzerland. This article is an open access article distributed under the terms and conditions of the Creative Commons Attribution (CC BY) license (http:// creativecommons.org/licenses/by/4.0/). 